\section{CORRECTION}

View Article Online

View Journal I View Issue

\title{
Correction: Anti-diabetic activity of peony seed oil, a new resource food in STZ-induced diabetic mice
}

Cite this: Food Funct., 2015, 6, 3400

\section{Jianhui Su, ${ }^{a, b}$ Hongxin Wang, ${ }^{a, b}$ Caoyang Ma, ${ }^{a, b}$ Zaixiang Lou, ${ }^{a, b}$ Chengxiang Liu, a,b MdRamim Tanver Rahman, ${ }^{a, b}$ Chuanzhong $\mathrm{Gao}^{c}$ and Rongjing Nie}

DOI: $10.1039 / c 5 f o 90034 d$

www.rsc.org/foodfunction
Correction for 'Anti-diabetic activity of peony seed oil, a new resource food in STZ-induced diabetic mice' by Jianhui Su et al., Food Funct., 2015, 6, 2930-2938.

In the original article, the Latin name for the tree peony under study was stated incorrectly. The correct Latin name for this species is Paeonia suffruticosa Andrews.

The Royal Society of Chemistry apologises for these errors and any consequent inconvenience to authors and readers.

\footnotetext{
${ }^{a}$ State Key Laboratory of Food Science and Technology, School of Food Science and Technology, Jiangnan University, Wuxi 214122, China.

E-mail: wanghongxin2009@hotmail.com; Tel: +86 510 85917795; Fax: +86 51085329276

${ }^{b}$ National Engineering Research Center for Functional Food, Jiangnan University, Wuxi 214122, China

${ }^{c}$ Anhui Tongling Ruipu Peony Industry Development Co., Ltd, Anhui 244000, China
} 